to plan for the future, and frustration of drives. ${ }^{1}$ Common reactions to such stress include depression, anxiety, and irritability. When $\mathrm{Abram}^{2}$ studied patients' adjustment to life during treatment by maintenance haemodialysis, he found a high incidence of depression during convalescence and when the patient began to face reality. Levy and Wynbrandt ${ }^{3}$ tried to assess the quality of life in 18 patients having maintenance haemodialysis. Several of them reported a drop in their income and a deterioration in family life as a result of this treatment, together with diminished frequency of sexual activity. Women appeared to adjust more successfully than men, few of whom could return to full employment. Both $\mathrm{Abram}^{2}$ and Kaplan De Nour ${ }^{1}$ believe that psychotherapy has a place in the management of such patients.

Renal transplantation is usually regarded as less stressful than maintenance haemodialysis because there should be less dependency on machines and on nursing, technical, and medical staff and the family. Nevertheless, patients who have had transplants have to cope with changes in body image due to steroid treatment and the risks and implications of graft rejection. ${ }^{4}$ Many of them, also, still have varying degrees of chronic renal failure and associated complications such as hypertension requiring continuous drug treatment.

Posnanski et $a l^{5}$ examined the quality of life in 18 children and adolescents after renal transplantation. They compared nine patients with good renal function on low doses of steroids with nine who were undergoing intermittent short-term or long-term rejection and were receiving high doses of steroids. Not surprisingly, those with a good functioning renal transplant fared very much better; seven of the nine were at school or work full time. Of those with impairment of renal function, only three were working full time. These latter patients were particularly concerned about change in their body image, especially their facial appearance, increasing weight, and reduced height, especially the adolescents. Only one of the nine was not depressed.

More recently Kaplan De Nour and Shanan ${ }^{6}$ compared the quality of life in 20 patients having dialysis and in 11 patients with transplants. Vocational rehabilitation was only slightly better in the transplanted patients with no differences in the social activities of the two groups. Nevertheless, two-thirds of the transplanted patients but only one-third of those on dialysis were free of psychiatric complications such as anxiety, depression, suicidal tendencies, or psychotic symptoms. Kaplan De Nour and Shanan ${ }^{6}$ suggest that the steroid treatment received by patients who have had transplants is responsible for their greater sense of wellbeing-despite the fact that in terms of vocational rehabilitation and social activities they do no better than the patients having dialysis. The dose of steroids being taken by their patients was not stated. The final word on this might perhaps be left to the patients: apparently none of those with transplants wished to return to dialysis but half of those having dialysis requested transplantation.

Have recent technical changes in dialysis and transplantation improved the quality of life for such patients? Probably yes. The tendency to dialyse for shorter periods, the reuse of artificial dialysers, and the increasing use of disposable dialysers have all helped to reduce the burdens associated with maintenance haemodialysis. In renal transplantation the tendency to use smaller doses of steroids than previously should reduce problems due to their side effects. Finally, if the problems of peritoneal infection can be solved then continuous ambulatory peritoneal dialysis may find an important place in the management of some patients.

1 De Nour AK. Psychotherapy with patients on chronic haemodialysis. Br f Psychiatry 1970;116:207-15.

${ }^{2}$ Abram HS. The psychiatrist, the treatment of chronic renal failure and the prolongation of life: II. Am $\mathcal{F}$ Psychiatry 1969;126:157-67.

${ }^{3}$ Levy NB, Wynbrandt GD. The quality of life on maintenance haemodialysis. Lancet $1975 ; \mathrm{i}: 1328-30$.

4 Abram HS. The psychiatrist, the treatment of chronic renal failure and the prolongation of life: III. Am $\mathcal{f}$ Psychiatry 1972;128:1534-9.

5 Posnanski EO, Miller E, Salguero C, Kelsh RC. Quality of life for longterm survivors of end-stage renal disease. $\mathcal{F} A M A$ 1978;239:2343-7.

${ }^{6}$ De Nour AK, Shanan J. Quality of life of dialysis and transplanted patients. Nephron 1980;25:117-20.

\section{Microwaves: a paper tiger}

In the developing years of our manufacturing economy environmental and occupational hazards were largely ignored. Nevertheless, once Simon ${ }^{1}$ and his contemporaries had produced the evidence that pollution of the environment caused diseases, control measures were introduced--often as a result of public pressure. The notable exception was atmospheric pollution. It took over 100 years of epidemiological effort and the great London smog of December 1952 to get an effective Clean Air Act on the Statute Book.

Nowadays, the pendulum seems to have swung too far in the other direction. Many technical developments are criticised on liealth grounds on mere suspicion with no hard evidence to support the condemnation. A recent example has been the scare raised about microwaves. These are non-ionising electromagnetic radiations in the frequency range of 30-300 000 megahertz $(\mathrm{MHz})$. Microwave radiation is emitted from electronic devices, including diathermy units, heating devices, television receivers, communication radar units, and some domestic ovens. Such waves generate heat at points close to the sources and so can cause thermal damage. Nevertheless, recent reports have alleged other effects from low intensities of microwave radiation, including changes in the cardiovascular and peripheral nervous systems. Some genetic effects have also been claimed, and these have been highlighted by newspapers and broadcasting services.

What is the reality ? At a recent symposium at the New York Academy of Medicine, ${ }^{2}$ Eisenbud assessed our state of knowledge on damage from microwave radiation and showed that after 40 years' experience of their use there is no evidence of damage to man. The only possible exception is cataracts, which may have been caused in workers using microwaves in industry. Clearly, however, surveillance should continue, including detailed epidemiological investigations.

Microwave radiation seems to have provoked some community groups into unreasonable responses, based on emotion and inconclusive biological research rather than scientific evidence. Public watchdogs have become part of our society, but their barking is constructive and beneficial only when supported by reliable evidence. At present, the evidence on microwave devices is that-if properly used-they are safe.

\footnotetext{
1 Simon J. Public health reports. Vols I, II. London: Churchill, 1887.

2 Eisenbud M. An overview. Bull NY Acad Med 1979;55:1274-8.
} 